\title{
Philosophies Underlying the Western and \\ Chinese Traditional Cultures
}

\author{
Yujun Liu \\ School of Foreign Languages, Qingdao University of Science and Technology \\ Box 502, 67 Songling Road, Qingdao 266061, China \\ E-mail: lyjlotus@126.com
}

\begin{abstract}
This paper aims at analyzing the distinctive features of the western and Chinese philosophies, which underlie the western and Chinese cultures. Westerners focus on the form, and they are deeply influenced by geometry and materialized philosophies. Meanwhile, Chinese people focus on connotation, and they are greatly influenced by the yin-and-yang principle.
\end{abstract}

Keywords: Form, Connotation, Materialized philosophy, Yin-and-yang principle, Five-element principle

\section{Aristotle and Liu Xie: Representatives of western and eastern cultures}

\subsection{Similarities}

"Art imitates nature". That is a very important viewpoint in art held by Aristotle. Literature, as a branch of art, imitates nature as well. And "nature" in the west, refers to natural beings such as plants, animals, and the human beings. As one of the forefathers of the western philosophers and literary critics, Aristotle exerted a deep and enduring influence on the British literature. Therefore I choose Aristotle as the spokesman for the British culture.

As for the spokesman for Chinese culture, we choose Liu Xie, an ancient Chinese scholar. In his famous Intention and Ornament in Literature, Liu Xie points out that literary works are created in accord with the natural laws of the universe. The sun, moon, rivers, plants, animals and human beings, which are depicted in literary works are in accord with the common logos, which is believed to be the transcendent reason or the rational principle expressed in words and things, although each has its specific characteristics.

Concerning literary creation, both Liu Xie and Aristotle stress the nature. But Lie Xie has gone much further into the natural laws than Aristotle.

\subsection{Differences}

For Aristotle, “..., art finishes the job where nature fails or imitates the missing parts.”(Shirley Wood, 1997: 30) Accordingly, it is human beings who make the art pieces. And he also pointed out, "since the objects of imitation are men in action, and these men must be either of a higher or a lower type (for moral character mainly answers to these divisions, goodness and badness being the distinguishing marks of moral differences), it follows that we must represent men either as better than in real life, or as worse, or as they are."(Zhang Zhongzai, 2002: 35) It shows that in the westerners' eyes, human beings are both the reproducers of the nature and an object of the imitation.

But in Liu Xie's opinion, human beings are only one small part of the universe, who are living in harmony with the nature. Like most traditional Chinese writers, he believes that human beings cannot be separated from the universe, and they are of one integrated entity.

\section{A survey on the traditional Chinese and western sense of culture}

\subsection{Western cultural sources with illustrations}

In Zhang Fa's Aesthetics and Cultural Spirit, Chinese and Western, he states that western culture originates from geometry, from which the model of science comes. Later on, contemporary scientists and philosophers continued to present a series of paradigms to describe the universe. A philosopher, Parmenides took "being" as the noumenon of the universe. Aristotle used "substance" to substitute for "being", which determined the direction of the development of 
western culture. The world depicted by artists is made up of substance and void. In westerners' mind, the two parts exist independently. As a result, the westerners pay more attention to "form" but less to the "content" of the things around them. For instance, facing a house, they catch the first sight of its pillars, walls, and roofs but not the void parts. Facing the body, they pay more attention to its proportion, but not the charm of the figure's temperament. When studying the laws of the universe, they focus on the logical inference of its ideational evolution. In a word, westerners' sense of culture is to take the existence of the world as a "form". From Parmenides and Plato, to Newton and Einstein, no philosopher or scientist is an exception. Although Einstein developed his wider-ranging Theory of Relativity, his equations can only be applied within a certain scope. He stepped forward a little further than others, yet he never broke away from the western mode of thinking, taking the world as a substantial form.

Labov has divided a fully-fledged narrative in the casual conversation into six parts (Huang Guowen, 1988: 147). The first part is an abstract, which gives the readers a brief introduction to the narrated story. The second is an orientation, which introduces the time, place, characters, and circumstances. The third is the complicated action, which serves as the development and climax of the story. The fourth is evaluation, which exists in any possible part of the story to express the writer's attitude or to arouse the reader's interest. The fifth is the result or resolution that ends the happening. The sixth is the coda, which echoes the theme. Among the six parts, coda is optional. Labov also points out that a fully-fledged narrative should consist of at least the first five parts. His statement coincides with the stereotyped writing mode of four steps in the composition of Chinese essays, which consist of introduction, elucidation of the theme, transition, and summing up.

In literature, we find the formula for the beginnings of fables, myths and allegories are usually "Long, long ago...", "There was once a...", "Once upon a time...", etc. In spite of this, the main event is seldom introduced at the beginning. Neither is the background. But modern English writers emphasize individuality and originality. They tend to separate the part from the whole and spotlight self-identity. They omit the beginning and /or the end of the stories to achieve a specific effect. And they start their stories with a direct yet elaborate event. Furthermore, they finish stories with a surprise ending, which remains open to the audience. Take the beginning of Hemingway's short stories as an illustration.

"The Killers" by E. Hemingway begins with an action directly as follows:

"The door of Henry's lunchroom opened and two men came in. They sat down at the counter."

Another short story "The Happy Life of Francis Macomber" also adopts an abrupt start. Its readers will be carried away by:

"It was now lunchtime and they were all sitting under the double green fly of the dining tent pretending that nothing had happened".

The audience cannot help wondering: "Why did they pretend to do so?" And "What on earth has happened?" These introductory remarks are always attractive and original. They bring in suspended questions to the readers and define an exciting atmosphere.

The abrupt elaboration of an accident or the surprising end of a story is nothing but the application of literary creation. By omitting the starting coda or abstract, the author kindles the readers' fancy and interest. This may contribute to the westerners' originality and individualism.

\subsection{Chinese cultural sources}

Then how do the Chinese observe the world? In his book, Zhang Fa concludes that the Chinese emphasize "wholeness". When they watch a building, the Chinese never forget its void part. For example, their windows and doors are delicately decorated and several bamboos are planted in their empty yard to produce a lively atmosphere. When they draw a picture of a body, they weird their last touch of the brush on the eyes, which brings in the most lifelike effect. When studying the universe, they never separate mankind from either heaven or earth. Early in ancient times, they found that the logos is the yin-and-yang principle in Taoism and the five-element principle. Over the time, whether in philosophy, medicine or literary works, the Chinese have always been applying these natural principles consciously or unconsciously.

The Dream of the Red Chamber, as a classic representative of traditional Chinese literature, the American sinologist Andrew II Plaks analyzes the structure of The Dream of the Red Chamber. He generalized its structural features as complementary bipolarity and multiple periodicities. Complementary bipolarity is similar to the Chinese yin-and yang principle, one half of which is feminine and negative and the other half masculine and positive. Multiple periodicities are similar to the Chinese five-element principle, which consists of gold(corresponding to autumn), wood(corresponding to spring), water(corresponding to winter), fire(corresponding to early summer) and earth(corresponding to later summer).

In Codes: Language and Art, Yu Jianzhong and Ye Shuxian take the main thread of the story in The Dream of the Red 
Chamber is the love story of Lin Daiyu and Jia Baoyu. And the side thread is the history of Jia Mansion and Rong Mansion, which undergoes a process from their heyday to their doomsday. In accord with the yin-and-yang principle, the two threads symbolize how happiness and sorrow, unity and departure, success and failure in human life switch with each other. There are also cycles of five-element principle. For instance, the clue of many chapters is the temporal order of the four seasons. Daiyu's short life represents a complete cycle of the spring, which corresponds with the element of wood. As she was born in the year of wood, she became sick and weak in the hot summer and was on the verge of death in autumn. This can be well explained by the mutual promotion and restraint among the five elements (Yu Jianzhong and Ye Shuxian, 1988: 201).

In addition to the above principles, the characteristics of "unity of humanity and universe" can be reflected at the beginning of the work as well, which is different from the spotlighted "self" in the west. At the beginning of The Dream, a stone tells the audience the background of the story. The previous existence of the characters and the potential cause and effect of the conflicts in the novel are expounded for the convenience of unfolding the vast scenes.

This may serve as an illustration to reveal the Chinese tendency to take the whole circumstance into consideration. Traditional Chinese novels usually begin with the background of the story, and end with a corresponding end to echo. And the characters and incidents function as the five elements of metal, wood, wood, fire and earth to interact with each other. This complicated and roundabout way of writing usually puzzles many westerners.

\section{A summary: Traditional philosophies in the west and in China}

\subsection{Traditional philosophy in the west}

Traditional philosophy in the west is based on nature. Western philosophers start their research from geometry and even physics. For instance, geometry emerging in ancient Greece serves as the model for western science. And ancient Greeks take "water", "fire", "earth", and "air" as the four elements of the universe. Ancient Indians believed "earth", "fire", "wind" and "water" as the four elements of the universe. These ideas were replaced by atomic theory later on, therefore the westerners tend to be unified and western way of thinking is characterized to be logical, formal, simple, direct, clear and analytical. They separate man from nature, focus on the form, and are deeply influenced by geometry and materialized philosophies.

\subsection{Traditional philosophy in China}

Traditional philosophy in China focuses on man and society. Chinese philosophers are deeply influenced by yin-and-yang principle and five-element principle. They originated from Yin and Shang Period. They exert deep influence on Chinese philosophy and culture and become the underlying structure of Chinese culture.

Chinese take fire, water, wood, earth and gold as the five basic elements of the universe. Water is taken to be the origin of life. People live on the earth and grow plants on it. The emergence of fire betters the human life. Wood symbolizes the agriculture and gold is the symbol ancient metallurgy. As time went on, the number of five rooted in Chinese people deeply. The five elements were used to describe the seasons, organs in human body, medicine, food, color etc.

Yin-and-yang principle is based on binary oppositions. Yin represents being dynamic, hot, bright, strong, upward, active, outward, etc. Yang represents being static, cold, dark, weak, downward, inactive, inward, etc.

When analyzing an object, the Chinese tend to ponder from two opposite directions. Therefore they maintain the colorful appearance of the real world, and tend to think in dialectic, comprehensive, complex, and indirect way. Chinese way of thinking does not seem so logical, systematic, and accurate as westerners. Yet the Chinese writers' vivid and concise expression is very attractive.

\section{References}

Andrew H. Plaks. (1998). Chinese Narratology, Beijing: Beijing University Press.

Guo, Shangxing \& Sheng Xingqing. (1993), A History of Chinese Culture. Kaifeng: Henan University Press.

Huang Guowen. (1988). Text-An Interdisciplinary Journal for the Study of Discourse. Changsha: Hunan Education Press.

Lie, Xie. (1996), Intention and Ornament in Literature (interpreted by Mou Shijin). Ji Nan: Qilu Press.

Wood, Shirley. (1997), Encyclopedic History of English Literary Criticism. Kaifeng: Henan University Press.

Yu, Jianzhang \& Ye, Shuxian. (1988). Codes: Language and Art. Shanghai: Shanghai People's Publishing House.

Zhang, Fa. (1997). Aesthetics and Cultural Spirit: Chinese and Western. Beijing: Beijing University Press.

Zhang, Zhongzai. (2002). Selected Readings in Classical Western Critical Theory. Beijing: Foreign Language Teaching and Research Press. 